\section{A smart solution specifically for children}

According to the latest research, the number of 5-year-olds with tooth decay has dropped to its lowest level in almost a decade. Among other efforts, preventive dentistry has played a key role in this.

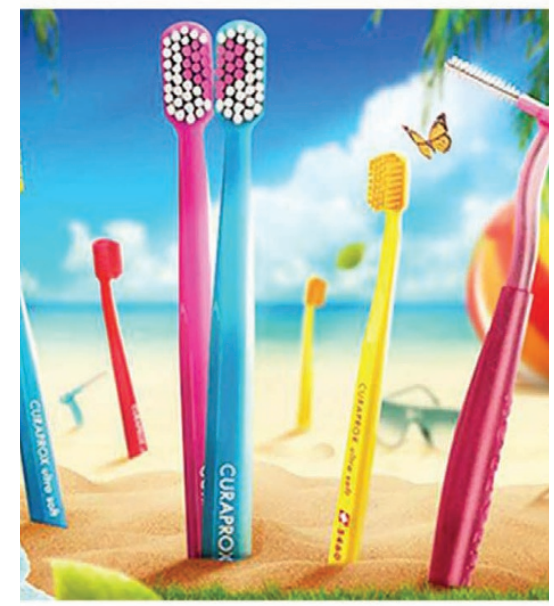

In order to achieve further reductions, practices must continue to encourage the use of safe, gentle and effective products.

Curaprox offers solutions that are the perfect combination of atraumatic and efficacious, making them ideal for protecting teeth against dental decay.

The CS Smart, which is specifically designed for children aged five and above, has an octagonal handle to encourage the correct cleaning angle as well as 7,600 extra-gentle and ultra-fine CUREN bristles for optimum cleaning.

With its small and compact head, the CS Smart is also ideal for targeting hard to reach areas.

To help further reduce dental decay in your five-year-old patients, contact Curaprox for advice on available solutions on 01480 862084 or visit www.curaprox.co.uk.

\title{
A look on the lite sidea
}

The Incognito Lite Appliance System from 3M Oral Care gives specialist orthodontists the leading edge in aesthetics and comfort.

Winner of the 2012 Red Dot Design Award, this solution for the anterior teeth minimises related discomfort and speech issues - patients can adjust in just three days.

Fitted to the lingual surface, away from view, it is a perfect solution for self-conscious adults. Affording ease of use to specialists with three-dimensional control, powerful torque, and Archwire bent to patients' needs, it's also the logical choice for mild to moderate overcrowding.

Offer your patients gold-star solutions that support your specialist standard of care: call the $3 \mathrm{M}$ Oral Care Team today. For more information, call 08456025094 or visit http://solutions.3m.co.uk/wps/portal/3M/en_GB/orthodontics_EU/Unitek/.

$3 \mathrm{M}$ and Incognito are trademarks of the $3 \mathrm{M}$ Company

\section{Advanced injectable practice training}

Aesthetic training academy MATA has launched a Postgraduate Award in Applied Clinical Facial Anatomy and Complications with award-winning Dalvi Humzah Aesthetic Training. Learners will have the opportunity to demonstrate advanced injectable practice on wet-tissue specimens with interactive discussion and assessment. The Level 7 postgraduate qualification reflects the content and competencies developed by the HEE, is awarded by EduQual and endorsed by TQUK, an Ofqualrecognised organisation.

The programme is underpinned by the evidence base and science behind materials and products used in current practice, providing learners with information on the efficacy, longevity and safety of injectables. Emphasis is given to the management of potential acute and late complications arising from cosmetic interventions through detailed study of applied clinical anatomy. The topics of pain control, patient anxiety and comfort are also taught and assessed.

To gain the qualification, learners will be required to complete written assessments and reflective portfolios to show how their clinical practice has been informed by anatomical teaching.

Delegates that have previously attended the Dalvi Humzah anatomy and complication courses can attend a fast-track conversion programme for the Level 7 qualification. Full details, fees and dates are available at: http://www.matacourses.com/

To register your interest, email info@matacourses.com and quote MATA-Dalvi.

\section{Don't lose out to tax}

Tax planning isn't just about staying compliant - it's about making the most of your money. Without advanced planning, every $£ 1$ you earn could end up being $16 \mathrm{p}$, the rest being whiled away in taxes.

Luckily there are ways to mitigate tax. For instance, you can make sure you claim all of your tax-deductible expenses, choose your accounting year-end wisely and maximise your pension and Independent Savings Account Annual Allowances.

To keep on top of reforms and ensure that your tax planning is executed to the highest standard, it is always best to utilise the services of expert accountants and an Independent Financial Adviser (IFA).

At the 4dentists group, experienced accountants and IFAs work together to manage your tax costs so that the most effective tax result can be achieved. There is a lot of money that can be saved - you just need to know where to target.

For professional, expert advice in reducing your tax bill, contact the 4dentists group.

For more information call 0845345 5060, email info@4dentistsgroup.com or visit www.4dentistsgroup.com. 